\title{
BIOLOGY OF THE PALM WEEVIL, RHABDOSCELUS MACULATUS IN SE- LECTED FOLIAGE PALM NURSERIES IN SRI LANKA
}

\author{
${ }^{1}$ MDSUKarunaratne, ${ }^{2}$ MMSC Karunaratne and ${ }^{3}$ HMRK Ekanayake \\ ${ }^{1}$ Tropiflora Limited, Lihiniwehera, Dodangaslanda, ${ }^{2}$ Department of Zoology, University of Sri Jayawar- \\ denepura, Gangodawila, Sri Lanka, ${ }^{3} 48$, Amunugama South, Gunnepana, Sri Lanka
}

Accepted: 22 September 2011

\begin{abstract}
A study on the Biology of the palm weevil Rhabdoscelus maculatus was carried out at Tropiflora Ornamental Palm Nurseries in Sri Lanka. This weevil, an important pest of ornamental palms, was detected for the first time in Sri Lanka at Tropiflora Nurseries. Although the incidence of this weevil is restricted to ornamental palms at present, there is a potential threat of the weevil becoming a pest of important cultivations such as coconut and sugarcane. The present investigation was therefore, carried out to confirm the identification of this weevil and to study its biology.

The identification of the palm weevil was confirmed as $R$. maculatus Gyllenhal, 1838 and is the first record in Sri Lanka. Biological, morphological and behavioural aspects of the weevil were studied under laboratory, semi-natural and natural conditions. The adult is a small, reddish-brown weevil (10.38$12.62 \mathrm{~mm}$ in length) with two black markings on the elytra and two on the thorax. The female is slightly larger than the male. The rostrum of the female is longer and more curved than that of the male. The ventral surface of the rostrum is roughened in the male while it is smooth in the female. Adult weevils are nocturnal in habit and hide in plant sheaths and debris during the day. They fly only short distances at a time but flight during the day was not observed. Mature female lays eggs inside cavities made in the leaf sheath. Under laboratory conditions, the period for egg incubation is $5.00 \pm 0.82 \mathrm{~d}$. The larva is creamy white and legless with a round, highly sclerotized, reddish brown head capsule. Larvae feed on stem tissues rapidly and make tunnels. The frequency distribution analysis of head capsule width revealed six larval instars. Early weevil infestation of palms is indicated by a jelly like substance oozing out of the holes in the leaf sheaths. $R$. maculatus larva takes about $7.75 \pm 3.70$ weeks to complete its development and then pupate inside a cocoon made of tightly bound, fibrous material completing the pupal stage in $2.50 \pm 0.76$ weeks. The total life cycle of this weevil is completed in 10-12 weeks. The life span of adult weevils is between 8-10 months under semi-natural conditions and four weevil generations per year occur under natural conditions.
\end{abstract}

Key words: Rhabdoscelus maculates, Palm weevil, Livistonia rotundopolia, Life history

\section{INTRODUCTION}

Pests and diseases are a major constraint in ornamental palm nurseries in Sri Lanka. Pest outbreaks directly affect the production of exportquality palm leaves and obtaining phytosanitory certificates for consignments.

The attack of the palm weevil Rhabdoscelus maculatus on the ornamental palms at the Tropiflora nurseries at Dodangaslanda was first observed in 1999 and a severe outbreak has occurred in 2000/2001. It is reported that Sugarcane (Saccharum officinarum) is the major host plant of $R$. obscurus (cane weevil borer), a similar pest found in New Guinea, Fiji, Australia and some other countries. However in Guam, $R$. obscurus is a major pest of ornamental palms, betel nut palm (Areca catechu), co- conut palm, (Cocos nucifera) and sugarcane, (Saccharum officinarum). The most affected plants of $R$. obscurus are reported as coconut, betel nut, champagne palm (Hyophorbe lagenicaulis), pritchardia palm (Pritchardia pacifica), pygmy date palm (Phoenix roebelenii), Alexander palm, (Archontophoenix alexandrae), royal palm (Roystonea regia) and date palm (Phoenix canariensis). Additionally, papaw (Carica papaya), sago palm, (Metroxylon sagu), banana (Musa sp.) and maize (Zea mays) are listed as minor hosts of $R$. obscurus (Halfpapp and Storey 1991; Muniappan et al. 2004; Napompeth et al. 1972). However, in Sri Lanka, the attack of $R$. maculatus is restricted only to ornamental palms in plant nurseries and has not so far become a pest of either coconut or sugarcane.

\footnotetext{
*Corresponding author: udayangani.karunaratne@gmail.com
} 
Although the incidence of $R$. maculatus at the moment is limited to ornamental palms, there is a very realistic risk of it becoming a pest of important cultivations such as coconut and sugarcane unless immediate actions are taken to control this pest. The present investigation was therefore, carried out to confirm the identity of this pest and also to study its biology and behavior under local conditions.

\section{METHODOLOGY}

A study on Biology of the palm weevil Rhabdoscelus maculatus was carried out at Tropiflora Nurseries at Dodangaslanda, Kandy and Green Farms at Marawila in Sri Lanka.

Identification of the weevil was made by Dr C HC Lyal, at The Natural History Museum, UK. Biological, morphological and behavioural aspects of the palm weevil were studied under natural, semi-natural and laboratory conditions.

\section{Egg laying behaviour and Incubation period of Eggs}

Egg laying behavior of the female and the incubation period of eggs were studied under laboratory conditions using three methods and each was replicated eight times.

\section{(i) Use of Livistonia rotundopolia sheaths with coir dust medium}

The bottom of an insect rearing box $(11 \mathrm{~cm}$ diameter) was covered with wet filter paper and a layer $(15 \mathrm{~cm}$ height) of coir dust was spread over it. Three leaf sheaths ( $8 \mathrm{~cm}$ length) of $L$. rotundopolia were placed on the coir dust (Plate 1). Seven- days - old one male and two female weevils were then introduced into the rearing box. The rearing box was kept at $28{ }^{0} \mathrm{C}$. The moisture level in the rearing box was maintained at $78 \pm 4 \%$ throughout the observation period by moistening the inside of the box. Egg laying habit of the female and the time taken for eggs to hatch were observed for 14 days.

\section{(ii) Use of Livistonia rotundopolia sheaths only}

The procedure carried out was similar to the previous one (i), but without the coir dust medium (Plate2).

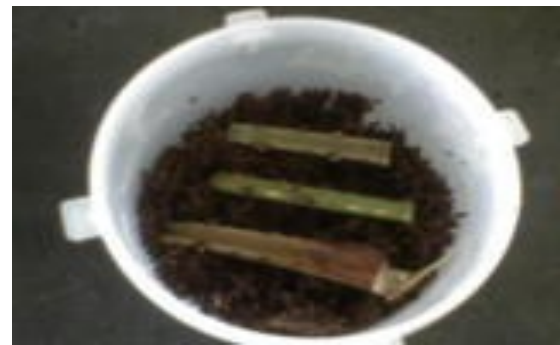

Plate1. Experimental set-up used to study the egg laying behaviour and incubation period of eggs of $\boldsymbol{R}$. maculatus on Livistonia rotundopolia sheaths with coir dust medium

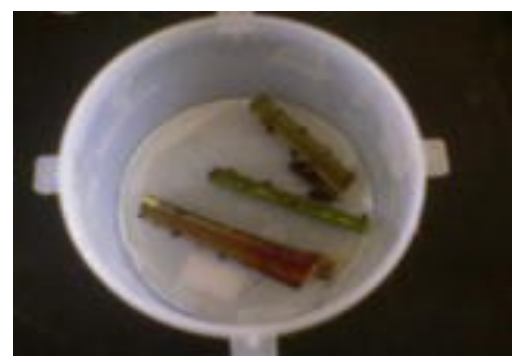

Plate2. Experimental set up used to study egg laying behaviour and incubation period of eggs of $R$. maculatus on Livistonia rotundopolia sheaths only

(iii) Use of Saccharum officinarum (Sugarcane) Stems

The hard outer skin of $S$. officinarum stem peeled off and cut into slices of 3-4mm thickness and $2.5 \mathrm{~cm}$ diameter were placed in transparent plastic boxes $(11 \mathrm{~cm}$ diameter) at the rate of 6 slices per box and covered with a lid (Plate 3 ). One week-old weevils (one male and two females) were then introduced into the box and allowed to lay eggs. After 24h, slices containing eggs were taken out and placed in separate petri-dishes bottom lined with wet filter paper until larvae emerged. In addition, some eggs were dissected out of the sugarcane slices after 2 to 3 days, to study their morphological characteristics. Relative humidity in the plastic box and petri-dishes with sugarcane stem slices was maintained at $75 \pm 4 \%$ throughout observation period by moistening the filter papers whenever necessary.

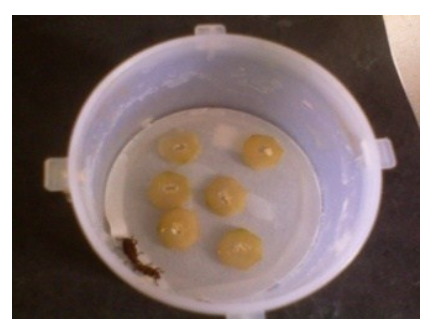

Plate 3. Experimental set up used to estimate egg laying behaviour and incubation period of eggs of $\boldsymbol{R}$. maculatus on sugarcane stems pieces 


\section{Duration of Larval and Pupal Stages}

To study the time taken to complete the larval and pupal stages under laboratory conditions, a tunnel at the top (about $5 \mathrm{~cm}$ long and $2 \mathrm{~cm}$ wide) was made in a sugarcane stem with four nodes $(90 \mathrm{~cm}$ long). Ten days old weevil larvae (collected from experiment iii) were placed inside the tunnel (1 larva/stem). The stems with the larvae were then placed in a plastic bucket $(50 \times 30 \mathrm{~cm})$. The sugarcane stems were placed in such a way that the end of the stem in which the larvae were introduced, was towards the bottom of the bucket. The top of the bucket was then covered with a wet cloth to prevent the stem being dehydrated and $\mathrm{RH}$ inside the bucket was kept at approximately $100 \%$. Observations were made every other day by slicing off stems and recording the time taken for larvae to become pupae and pupae to adults. This experiment was replicated five times.

\section{Determination of larval instars}

A study was carried out to determine the number of larval instars of $R$. maculatus based on the distribution of their head capsule widths. Two hundred larvae, collected randomly in the field, were killed and preserved in $70 \%$ ethyl alcohol. Head capsules of these larvae were measured across their widest point using an electron scanning microscope. The results were plotted against observed frequencies.

Similarly, the number of instars was determined from larvae reared under laboratory conditions $\left(28+2^{0} \mathrm{C}\right.$ and $\left.80 \%+3 \mathrm{RH}\right)$. In this instance, thirty newly emerged larvae were introduced into sugar cane stems (1 larvae/stem). One larva was extracted from a stem once in three days by slicing them carefully and the width of the head capsules was measured. This experiment was replicated 7 times. These results were also plotted against observed frequencies. The mean width of the head capsule of larvae was computed for each instar, with the mean consecutive geometric progression according to Dyar's Rule (Hutchinson et al. 1997).

\section{Life history of $\boldsymbol{R}$. maculatus under semi- nat- ural and natural conditions}

Life History of $R$. maculatus was studied under semi- natural and natural conditions. One male and two females of $R$. maculatus adults (7 days old) were introduced onto one year old potted palms (Livistonia rotundopolia) covered with insect-proof mesh and kept in cages $(180 \mathrm{~cm} \mathrm{x}$ $120 \mathrm{~cm} \times 180 \mathrm{~cm})$. Egg laying behavior of the female, life cycle and damage symptoms due to pest attack were observed. Similar observations were also made in the field under natural conditions. This experiment was replicated six times.

\section{RESULTS AND DISCUSSION}

The weevil under consideration was identified and confirmed as Rhabdoscelus maculatus. It belongs to the order Coleoptera, the superfamily Curculionoidea and the family Dryophthoridae.

\section{Egg laying behaviour and incubation period of eggs}

Normally the female weevils lay eggs in small cavities on palm leaf sheaths, made by the ovipositor. One probable reason for this behavior may be to prevent exposure of eggs to the outer environment. However, in the present study, the females when introduced onto palm sheaths with coir dust medium laid eggs on the sheaths without making any cavities. Also, they laid eggs on coir medium. However, eggs which were laid on the leaf sheath and coir dust did not hatch and they dried up eventually, may be due to unsuitable and exposed conditions. The experiment which was carried out without coir dust was unsuccessful as the female weevils did not lay eggs at all under these conditions. Females laid eggs singly in small cavities (2 to $3 \mathrm{~mm}$ deep) made on sugarcane stems (Plate 4) and the incubation period of eggs was $5.0 \pm 0.82$ days.

Of the three different methods (methods i, ii and iii) tested, presenting sugarcane stem slices to the female weevils was found to be the best method under laboratory conditions for oviposition and for the eggs to hatch. Interestingly, Napompeth et al. (1972), testing 18 natural, artificial and semi-artificial rearing media for the New Guinea sugarcane weevil, R.obscurus have reported that only shredded coconut husk and sugarcane stalks gave promising results. Also, under laboratory conditions, the Asiatic palm weevil, R. lineatocollis did not oviposit on hard and soft sugarcane varieties. However, when the stems were artificially cracked by a 
knife, eggs were laid in the cracks. Also, it was reported that when the epidermis was totally removed, the number of eggs laid has been increased (Takahashi et al. 1998).

\section{Duration of larval and pupal stages}

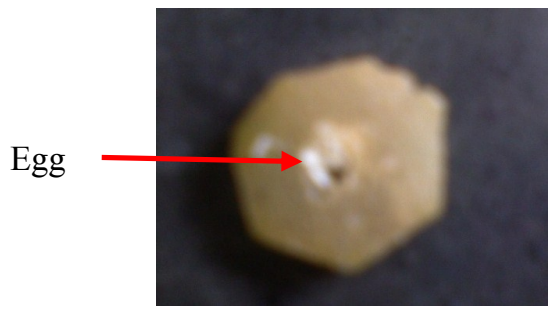

Plate 4.Egg laid in Sugarcane Slice

According to the results, the larval development (time taken for larvae to become pupae), has taken 7 to 9 weeks $(54.00 \pm 29.26$ days $)$ and 2 to 3 weeks $(17.50 \pm 8.69$ days) was taken for pupation (time taken for pupae to become adults) under laboratory conditions.

\section{Determination of larval instars}

According to Dyar's Law the analysis of the data obtained from the field collected larvae revealed 6 larval instars and a prepupal stage. In this experiment, the mean width of the head capsules of the larvae was computed for each instar, with the consecutive geometric progression averaging 1.39 (Table1). Based on Dyar's Rule, a geometrical progression of head widths can be represented by a straight line if the head measurements (Y) were plotted against the number of instars $(\mathrm{X})$.

Figure 1 shows the straight line relationship between larval instars including the pre-pupal stage and width of the head capsule expressed in logarithms. The regression equation was, $\mathrm{Y}=$ $0.1416 \mathrm{x}-0.4431$. With this relationship it was possible to estimate the number of larval instars by measuring the width of the head cap-

Table1.Number of larval instars, observed width, geometric progression and theoretical width of larval instars of Rhabdoscelus maculatus

\begin{tabular}{lllllll}
\hline $\begin{array}{l}\text { No. of } \\
\text { Larval } \\
\text { Instars }\end{array}$ & $\begin{array}{l}\text { Ob- } \\
\text { served gression } \\
\text { Width }\end{array}$ & \multicolumn{2}{l}{$\begin{array}{l}\text { Geometric Pro- } \\
\text { Width }\end{array}$} \\
\hline 1 & 0.5 & $0.73 / 0.5$ & 1.42 & 0.5 & & Log \\
2 & 0.71 & $1.01 / 0.73$ & 1.42 & $0.5 \times 1.39$ & 0.50 & -0.3 \\
3 & 1.01 & $1.48 / 1.01$ & 1.48 & $0.69 \times 1.39$ & 0.96 & -0.0161 \\
4 & 1.49 & $1.98 / 1.48$ & 1.25 & $0.96 \times 1.39$ & 1.33 & 0.123 \\
5 & 1.86 & $2.45 / 1.98$ & 1.32 & $1.33 \times 1.39$ & 1.85 & 0.261 \\
6 & 2.46 & $3.52 / 2.45$ & 1.43 & $1.85 \times 1.39$ & 2.56 & 0.408 \\
Prepupa & 3.52 & & & $2.56 \times 1.39$ & 3.55 & 0.55 \\
\hline
\end{tabular}

sule. Hsia and Kao (1987) in their studies on Helicoverpa armigera noted that a geometrical progression of the head width can be represented in a straight line and it fitted the Dyar's rule very well.

A histogram of head capsule widths of labora-

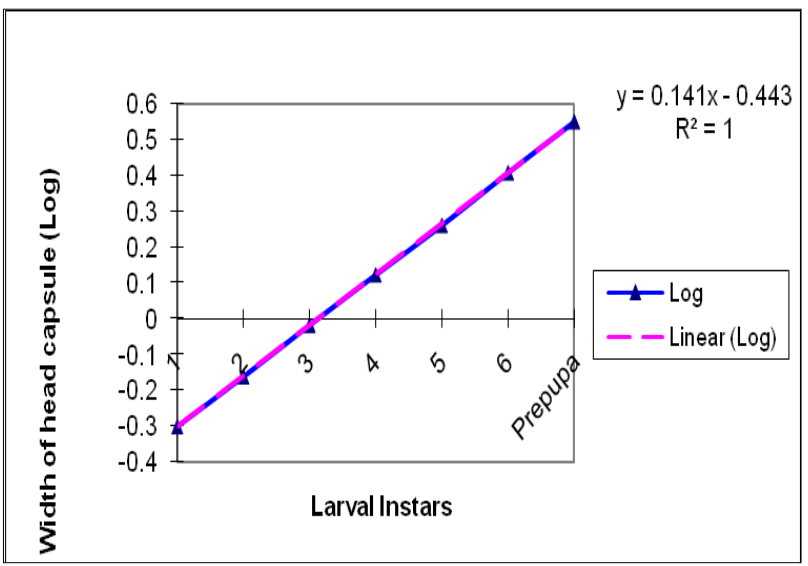

Figure 1Relationship between the Width of the Head Capsule and the Larval Instars and Prepupa of Rhabdoscelus maculatus

tory reared larvae is presented in Figure 2. Thus, the total number of peaks represented in a head capsule size frequency distribution, shows the total number of instars in a species (Schmidt et al. 1977). It is assumed that each peak represents an instar and the distribution of the head capsule sizes in each instar has a normal distribution (Caltagirone et al. 1983). The frequency distribution analysis of head capsule width revealed six distinguishable larval instars (Figure2). Therefore, each peak within the distribution was assumed to correspond to an individual instar of $R$. maculatus.

Life history of $\boldsymbol{R}$. maculatus under semi- nat-

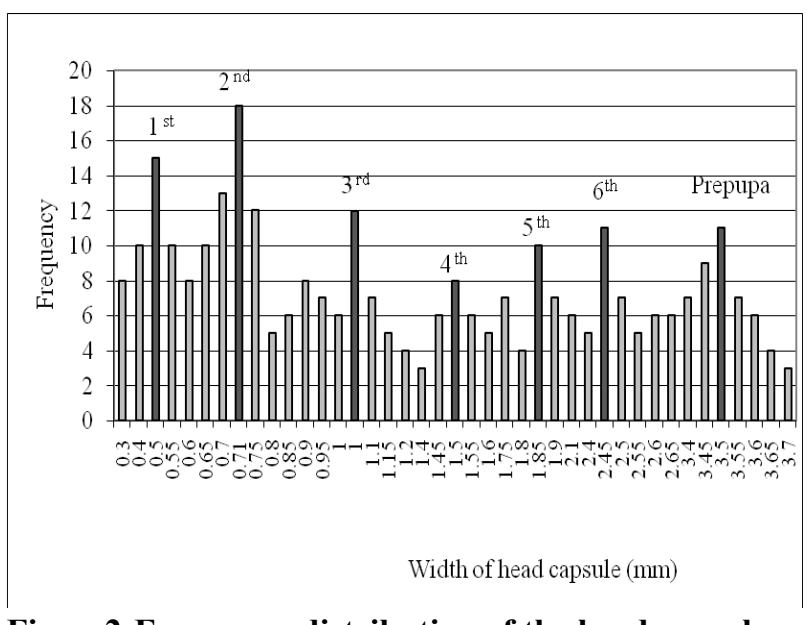

Figure2:Frequency distribution of the head capsule width of larvae and pre-pupae of Rhabdoscelus maculatus using laboratory samples 


\section{ural and natural conditions}

Adult weevils usually hide under leaf sheaths of the palm during the day. They are nocturnal in habit and feed on the plant sap. Adult $R$. maculatus is moderately a large reddish brown weevil with a rather oblong body. It has two black markings on each elytron and two on the thorax (Plate 5). The average adult is 10.38$12.62 \mathrm{~mm}$ long and $3.5-5.0 \mathrm{~mm}$ wide.
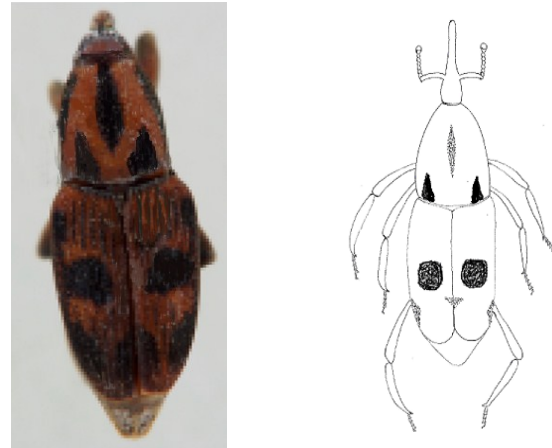

Plate 5. Dorsal view of adult $R$. maculatus

Palm weevils show sexual dimorphism. The female is comparatively larger than the male. The ventral surface of the rostrum is smooth in the female and rough and less curved in the male (Plate 6) (a)

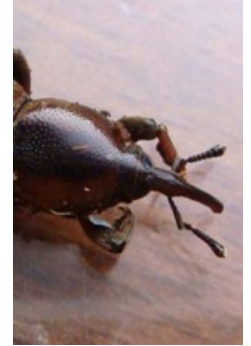

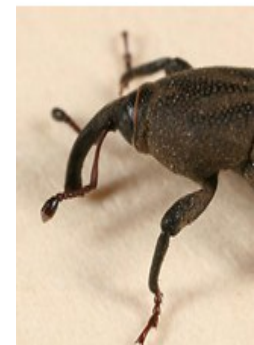

Plate 6. Adult $R$. maculatus; a) Male rostrum;

(b) b) Female rostrum

The mature female chews a small cavity (2$3 \mathrm{~mm}$ deep) in the rind of the sheath or splits the sheath tissue with her mandibles. Into each cavity, a single egg is deposited. Eggs can also be laid in cracks in the stem. Newly laid eggs are elongated, smooth, translucent white, and slightly curved with rounded ends (Plate 6). These are about $1.0-1.5 \mathrm{~mm}$ long. Eggs take about $5 \pm 0.82$ days to hatch.

The larva is a creamy-white legless grub with a curved body which is sparsely covered with stiff, short hairs. The reddish-brown head and the mouthparts are well developed and are highly sclerotized (Plate 8). The larva when emerged is $1.5-2.0 \mathrm{~mm}$ long and the fully

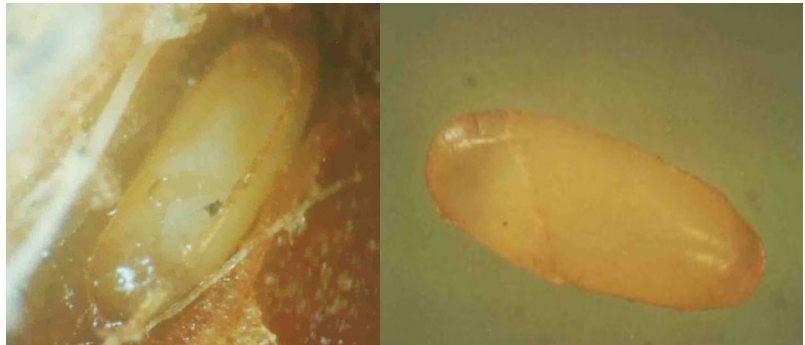

Plate 7. Eggs of Rhabdoscelus maculatus (1x 20)

grown larva is $12.9-15.5 \mathrm{~mm}$ in length. After hatching, the larva burrows down the leaf sheath and enters the trunk. It feeds on the stem tissues tunneling up and down. With the growth of the larva, the tunnels made become correspondingly larger. Therefore, the diameter of the tunnel varies with the size of the larval stage. Generally this is between $5-7 \mathrm{~mm}$. A single larva lives in its own tunnel. This may be due to their cannibalistic nature (Napompeth et al. 1972). Usually, 2-7 larvae of different larval stages can occur in one plant. Larval tunnels are usually blocked at the entrance by a plug of plant fiber. Tightly packed, fine pieces of fiber are always observed in the tunnel behind the larvae.

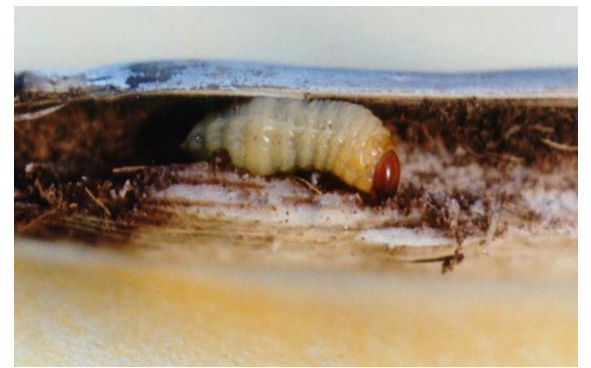

Plate 8. Rhabdoscelus maculatus larva inside a tunnel (1 x1)

Infestations of the weevil are noted by a jellylike substance oozing out from the holes in the leaf sheaths. Moreover, infested plants emanate a 'fermenting odour'. After about 20-25 days, larvae burrow into the bud of the palm feeding on the young tissues. Buds can be easily removed from the attacked plants and the other leaves die later on. In younger palms, the larvae mine the central portion of the stem, thus completely destroying the plant. Larval development takes $54.0 \pm 9.26$ days.

Pupation starts with the larva constructing an oval and elongated, tightly bound, fibrous cocoon inside the trunk (Plate 9). The final instar larva remains inside the cocoon for a few days before pupating. The pupa is about 17.36- 
$19.04 \mathrm{~mm}$ (mean $18.20 \pm 0.84 \mathrm{~mm}$ ) in length. Pupation is completed in $17.50 \pm 8.69 \mathrm{~d}$. The adult does not emerge from the cocoon immediately, but remains inside it for about 12 days. It chews and makes a small exit hole in the cocoon and cuts its way out of the palm eventually.

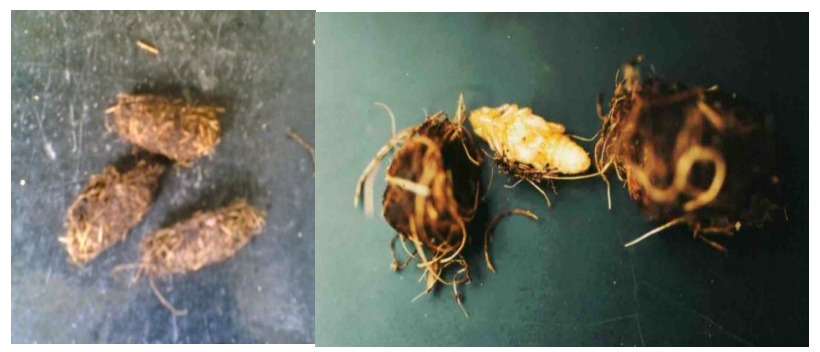

Plate 9. Pupal cocoons and pupae of Rhabdoscelus maculatus (1x1)

The total duration of the life cycle of $R$. maculatus (time taken from oviposition to F1 adult emergence, both of which can be observed) was 10-12 weeks. This value represents the egg incubation period and larval and pupal periods as a whole. Determining the time taken for various stages of the life cycle of $R$. maculatus is extremely difficult under semi-natural and natural conditions as they occur inside palm sheaths and cutting open a sheath will destroy the egg, larval and pupal stages as well as their natural habitats. Thus, time duration for egg incubation (5.0 days), larval period (54.0 days) and pupal period (17.50 days) observed under laboratory conditions were included to determine the duration of the life cycle of $R$. maculatus.

The present study revealed that adult $R$. maculatus weevils live between 8-10 months under semi-natural conditions. It is reported that adult $R$. obscurus, which is well- studied and closely related to $R$. maculatus can live up to about 10 months under natural conditions. However, in laboratory experiments, the longevity of this weevil was reported to be 160 days (Napompeth et al. 1972). Leather (1990) stated that the influence of host plant food quality may have a significant impact on longevity of adult weevils. Adults normally do not do any economic damage to the host plant. The most serious damage is caused by the larval stage. Long term observations of the life cycle of $R$. maculatus in palm fields indicated four weevil generations per year.

\section{REFERENCES}

Caltagirone LE, Getz W, and Meals DW 1983 Head capsule width as an index of age in larvae of navel orangeworm, Amyelois transitella (Lepidoptera: Pyralidae). Environ. Entomol. 12: 219-221.

Halfpapp KH and Storey RI 1991 Cane weevil borer, Rhabdoscelus obscurus (Coleoptera: Curculionidae), a pest of palms in Northern Queensland, Australia. Principes 35: 199-207

Hsia WT and Kao SS 1987 Application of head width measurements for instar determination of corn earworm larvae. Plant Prot. Bull. 29:277282

Hutchinson JC, Mcnamara JM, Houston AI and Vollraths F 1997 Dyar's Rule and the Investment Principle: optimal moulting strategies if feeding rate is size-dependent and growth is discontinuous. Phil. Trans. R. Soc. Lond. B 352: 113-138.

Leather SR 1990 Life History traits of insect herbivores in relation to host quality, pp. 175-207 In E. A. Bernays [ed.], Insect-plant Interactions, Vol. V. CRC Press, Boca Raton. 305.

Lyal CHC, Beetle Diversity and Evolution Programme, Department of Entomology, The Natural History Museum, London. (Personnel Communication)

Muniappan R, Bamba J, Cruz J, and Reddy GVP 2004 Field Response of Guam Populations of the New Guinea Sugarcane Weevil, Rhabdoscelus obscurus (Boisduval) (Coleoptera: Curculionidae), to Aggregation Pheromones and Food Volatiles. Micronesica 37(1):57-68.

Napompeth B, Nishida T and Mitchell WC 1972 Biology and rearing methods of the New Guinea sugarcane weevil, Rhabdoscelus obscurus. Hawaii Agricultural Experiment Station, Technical Bulletin No.85. 51p.

Schmidt FH, Campbell RK and Trotter SJ 1977 Errors in determining instar numbers through head capsule measurements of a lepidopteran-a laboratory study and critique. Ann. Entomol. Soc. Am. 70:750-756.

Takahashi K, Mitsutaka S, Takayoshi T and Hiroshi S 1998 Oviposition preference and larval development of Rhabdoscelus lineatocollis (Coleoptera: Rhynchophoridae) in sugarcane Applied Entomology and Zoology Vol 33: 409411 